\title{
RNA seq analysis of potato cyst nematode interactions with resistant and susceptible potato roots
}

\author{
Abigail J. Walter • Jakob Willforss • Marit Lenman • \\ Erik Alexandersson • Erik Andreasson
}

Accepted: 13 March 2018 / Published online: 20 March 2018

(C) The Author(s) 2018

\begin{abstract}
Potato cyst nematodes (PCN) are important pests in crop production, especially since they persist in the soil and may affect further potato production for many years. Little is known about putative resistance and susceptibility targets as well as the general signaling in potato after interactions with PCN. Here we characterize a new potato breeding clone, SW-1015, found to harbor resistance to Globodera rostochiensis pathotype Rol/4, the main PCN pathotype present in Sweden. SW1015 contains the $H 1$ resistance gene. We then describe susceptible and resistant reactions of potato infested by G. rostochiensis Ro1/4 in a global potato RNA-seq analysis. Only the resistant clone reacted to PCN infection quickly ( $8 \mathrm{hpi})$, and the reaction included upregulation of a TSRF1 transcription factor. $48 \mathrm{~h}$ after PCN infection, massive RNA reprograming was evident in both resistant and susceptible clones. In the resistant interaction, several genes were up-regulated including germins and a cysteine protease, as well as a laccase. In contrast, the susceptible interaction involved up-
\end{abstract}

Electronic supplementary material The online version of this article (https://doi.org/10.1007/s10658-018-1474-z) contains supplementary material, which is available to authorized users.

A. J. Walter · J. Willforss · M. Lenman · E. Alexandersson • E. Andreasson $(\square)$

Plant Protection Biology, Swedish University of Agricultural Sciences, P.O. Box 102, S-230 53 Alnarp, Sweden

e-mail: erik.andreasson@slu.se

Present Address:

A. J. Walter

USDA-APHIS Biotechnology Regulatory Services,

Riverdale, MD, USA regulation of genes for auxin transport and homeobox binding. Enriched GO terms for kinase activity, calmodulin, and $\mathrm{Ca}^{2+}$ ion binding in susceptible potato might reflect the initiation of nematode feeding structures. A TIR receptor like protein member was induced in the susceptible interaction only, making this a putative susceptibility factor. The RNA data is deposited at ArrayExpress with the number E-MTAB-5215.

Keywords PCN · TSRF1 Pit1 - Germins - Globodera rostochiensis · Désirée · SW93-1015

\section{Main text}

Potato cyst nematodes (PCNs), Globodera rostochiensis and G. pallida are some of the most damaging pests of potato crop worldwide. They account for yield loss of $9 \%$ per year of potato production (Jones et al. 2013), despite the fact that one or both species is absent from many of the major potato growing regions. In Sweden isolates of G. rostochiensis Ro1/4 and G. pallida $\mathrm{Pa} 2 / 3$ exist, and persist in the soil for many years, seriously hampering potato production in infested fields (Manduric 2004). One of the most practical management strategies for PCN is the use of resistant plants and therefore knowledge about resistance and susceptibility factors including effectortargets in potato is of great importance.

Plant defense strategies against nematodes have some similarities to defense against microbial pathogens, including strengthening of tissues through lignification, suberization and ferulic acid binding to cell walls 
(Walters 2010). When nematodes attack the roots of a plant, the plant may defend itself by PAMP-triggered immunity (PTI) or effector triggered immunity (ETI) (Hewezi 2015). The salicylic acid, jasmonic acid, and ethylene hormonal pathways may be activated during ETI, and cross-talk between the pathways may help to determine the specificity of the response (Thaler et al. 2012; Walters 2010). During susceptible nematodeplant interactions, nematode effectors may repress ETI and affect the development of nematode feeding cells and the architecture of cell walls. The mechanisms or action of nematode effectors include depolymerization of cell wall polysaccharides, mimicry of host signaling peptides, regulation of host auxin signaling, suppression of host defense and posttranslational modification of host signaling proteins (Hewezi 2015).

A global RNA analysis of the susceptible interactions between tomato and PCN has been done (Swiecicka et al. 2009). In that interaction, a cell wall peroxidase involved in lignification was repressed, leading to successful nematode infection and completion of the nematode life cycle (Portillo et al. 2013). Described effectors in the genus Globodera include CWMPs (cell wall modifying proteins), endoglucanases, pectate lyases, CBPs (cellulose binding proteins), EXPs (expansins); CLE-like (CLAVATA3/endosperm surrounding region) peptides, and SPRYSEC proteins. The CLE-like proteins of Globodera spp. may mimic the CLE peptides of the host plant development (Mitchum et al. 2012) and the SPRYSEC proteins suppress ETI responses (Mitchum et al. 2013). However, with the exception of some resistance genes (Hewezi 2015), little is known about resistant interactions between potato and PCN.

The goal of this study is to characterize the interaction between PCN and a promising potato breeding clone in Sweden and to study the molecular interactions of potato-nematode interactions. One population of G. rostochiensis pathotype Ro1/4 typically found in Sweden (Växtorp population) were periodically increased and used throughout the study. The wellcharacterized cultivar Désirée and the breeding line SW93-1015 were used for all experiments in this study (Ali et al. 2012, 2014). Plants were grown in vitro essentially as in Abreha et al. (2015). The presence or absence of nematode resistance gene $H 1$ was analysed by PCR using the two primer pairs N146 (5' AAGCTCTTGCCTAGTGCTC 3' and 5' AGGCGGAACATGCCATG 3') and N195 (5' TGGAAATGGCACCCACTA $3^{\prime}$ and 5' CATCATGG
TTTCACTTGTCAC 3'), giving products of 506 and $337 \mathrm{bp}$, respectively. PCR amplifications was done with $0.2 \mathrm{mM}$ dNTP, 0.2 U Taq DNA Polymerase and $0.5 \mathrm{~mm}$ of each primer. PCR was carried out on an Applied Biosystems 9700 thermal cycler (Life Technologies, Carlsbad, USA) using the following program: one cycle at $95{ }^{\circ} \mathrm{C}$ for $2 \mathrm{~min}$, followed by 35 cycles at $95^{\circ} \mathrm{C}$ for $10 \mathrm{~s}, 55{ }^{\circ} \mathrm{C}$ for $30 \mathrm{~s}$ and $72{ }^{\circ} \mathrm{C}$ for $1 \mathrm{~min}$, and then terminated with one cycle of $5 \mathrm{~min}$ at $72{ }^{\circ} \mathrm{C}$. PCR products were analyzed on $1 \%$ agarose gels. PCR showed that SW93-1015 contained both of the expected bands, while reactions from Désirée did not amplify any band (data not shown). Therefore we concluded that SW93-1015 contains the $H 1$ gene and Désirée did not.

The resistance phenotypes of the potato cultivars were determined in a 'closed container' test. Half tubers were soaked in a $0.054 \%(w / w) ~ N a O C l$ solution for two minutes, then rinsed in tap water and allowed to dry at room temperature overnight. The tubers were then added to $600 \mathrm{~mL}$ plastic containers containing $250 \mathrm{~g}$ of silver sand, $37 \mathrm{ml}$ of tap water and sealed off with a lid. The containers were placed at room temperature in the dark for 7-10 days to allow roots to grow, then 10 cysts were added to each container and the containers were closed again. The containers were placed in the dark at room temperature for 23 weeks (experiment 1) or 16 weeks (experiment 2). Nematodes were then extracted from the container using an Oostenbrink elutriator and the number of cysts were counted. The experiment was run twice, with five replicated containers of each clone in each experiment. The two experiments were pooled for analysis. The number of cysts on the two potato cultivars was compared by the nonparametric Kruskal-Wallis test with $p<0.05$. Clone SW93-1015 was shown to be resistant, with significantly fewer cysts recovered (Fig. 1). Since clone SW93-1015 is used in the Swedish potato breeding program (Eriksson et al. 2016) this information together with the marker information is useful for practice.

In order to investigate the potato response to G. rostochiensis Ro1/4 infection, we grew SW-1015 and Désirée potato in in vitro conditions, and examined changes in the potato transcriptome at two timepoints after PCN infection ( 8 and $48 \mathrm{~h}$ ). Juvenile nematodes were obtained by a modification of the method in Heungens et al. (1996). G. rostochiensis Rol/4 cysts were elutriated from soil and dried at room temperature. Excess soil or debris was brushed off with a fine paintbrush. Approximately 30 cysts were placed into a $20-\mathrm{mL}$ 


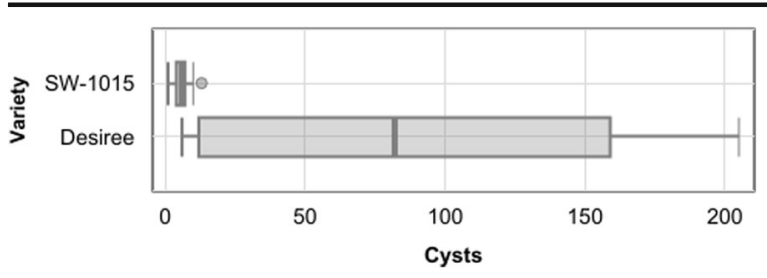

Fig. 1 Minimum, first quartile, median, third quartile, maximum, and outlier numbers of cysts of Globodera rostochiensis Ro1/4 recovered from after initial infection of Solanum tuberosum cultivar Désirée and S. tuberosum SW93-1015 with 10 cysts in each test. Differences between $S$. tuberosum genotypes were analyzed by the nonparametric Kruskall-Wallis test, and were significant at $p<0.001$

plastic syringe (Sarstedt, Nümbrecht. Germany) modified by having the tip end cut off, replaced with a $30 \mu \mathrm{m}$ mesh heat sealed across the tube. Cysts were washed with $90 \%$ EtOH for $15 \mathrm{~s}, 0.054 \%(w / \mathrm{w}) \mathrm{NaOCl}$ for $3-5 \mathrm{~min}$ and 3 times with water for $45 \mathrm{~s}$. The plunger was then removed from the syringes and the syringes containing PCN cysts were placed in $50 \mathrm{~mL}$ centrifuge tubes (Falcon Sarstedt, Nümbrecht, Germany) filled with autoclaved tap water. The centrifuge tubes and syringes were covered with paraffin film (BEMIS, Wisconsin, USA) and allowed to incubate in the dark at room temperature for 2-3 days. Potato root exudate was obtained by overwatering a Désirée potato plant grown in a pot filled with sand and collecting the water that flowed out of the bottom. The exudate was passed through a $0.2 \mu \mathrm{m}$ filter and stored in the dark at $4{ }^{\circ} \mathrm{C}$ for a maximum of 7 days. After $2-3$ days of soaking in sterile tap water, cysts were moved to centrifuge tubes containing filtered potato root exudate, resealed and left in the dark for 5-15 days. Every few days, the exudate was changed and the infective juvenile nematodes that had hatched and swum through the mesh into the centrifuge tube were collected. Solutions of infective juvenile G. rostochiensis Ro1/4 nematodes collected three days earlier were diluted to a concentration of 1000 nematodes $/ \mathrm{mL}$ in autoclaved tap water. Ten $\mu$ of the nematode solution or sterile tap water control were pipetted onto the root system of potatoes growing in vitro on thick agar such that the roots were located on the surface of the agar. The infected and control plants were returned to the growth chamber in a completely randomized design. At $8 \mathrm{~h}$ or $48 \mathrm{~h}$ after infection, the roots were removed from the plants by grabbing them with blunt forceps and peeling them off the agar. The roots were immediately frozen in liquid $\mathrm{N}_{2}$ and stored at $-80{ }^{\circ} \mathrm{C}$. Different plants were sampled for the two time points. RNA was extracted as described by Ali et al. (2014). ND-
1000 NanoDrop (Wilmington, USA) was used to check RNA concentration and purity while integrity of the samples was analyzed by using Experion ${ }^{\mathrm{TM}}$ Automated Electrophoresis System (Bio-Rad Laboratories, Hercules, USA). Sequencing was done using Illumina Hi seq.2000 machine. The RNA-seq reads were trimmed using Trimmomatic (Bolger et al. 2014; v0.30) with the following adjustment to the standard settings: ILLUMINACLIP:TruSeq3-PE.fa:2:30:10:1:true. Reference genomes were downloaded for Solanum tuberosum (Xu et al. 2011; Sharma et al. 2013) (v4.03). The number of reads mapped to each gene in Solanum tuberosum was counted using HTSeq-count (Anders et al. 2015) (v0.6.1p1) and the RNAseq data has been deposited in array express E-MTAB-5215. Differential gene expression analysis was carried out using the R/Bioconductor package DESeq2 (Love et al. 2014) (v1.10.1). The raw gene-count received from HTSeq-count was used as input. After quality filtering of the RNA seq data, 26$41 \mathrm{M}$ read pairs remained for each sample, with an average of $32 \mathrm{M}$ read pairs per sample. Mapping rates to the potato reference genome varied between $48 \%$ and $97 \%$ for the samples, with an average of $88 \%$. The varying mapping rate to the potato reference genome was investigated. Samples with lower mapping rates were not found to be outliers based on investigation of PCA component and of Cook's indices and were therefore not omitted from further analysis. Comparisons were made between inoculated and non-inoculated samples for each of the two clones and the two time points $8 \mathrm{hpi}$ and 48 hpi (Supplementary Tables 1 and 2). Each sample used in the comparisons were based on three biological replicates. Genes with a Benjamini-Hochberg adjusted $p$ value of less than 0.1 were deemed to be differentially expressed. The overall PCA analysis after transforming the data using DESeq2's regularized log transform show that the genotype difference constituted the major PC (Fig. 2a). After $48 \mathrm{~h}$ the inoculated samples could be grouped together (Fig. 2b). Gene ontology (GO) terms were assigned to transcripts using the best-performing functional annotation for the potato genome as determined by Amar et al. (2014). A GO enrichment analysis of the significantly differentially expressed genes was done in GOEast using default settings (RodríguezLópez et al. 2008). Differentially expressed transcripts was further analyzed in MapMan (Thimm et al. 2004), including a PageMan analysis of overrepresentation of MapMan functional bins, which is similar to a gene set enrichment analysis. 
Fig. 2 An overall PCA analysis of the RNA seq data. Upper part of the figure shows potato gene expression in samples (PC1 vs PC2), and lower part shows PC2 vs PC 3. After $48 \mathrm{~h}$ the inoculated samples could be grouped together (Fig. 2B)
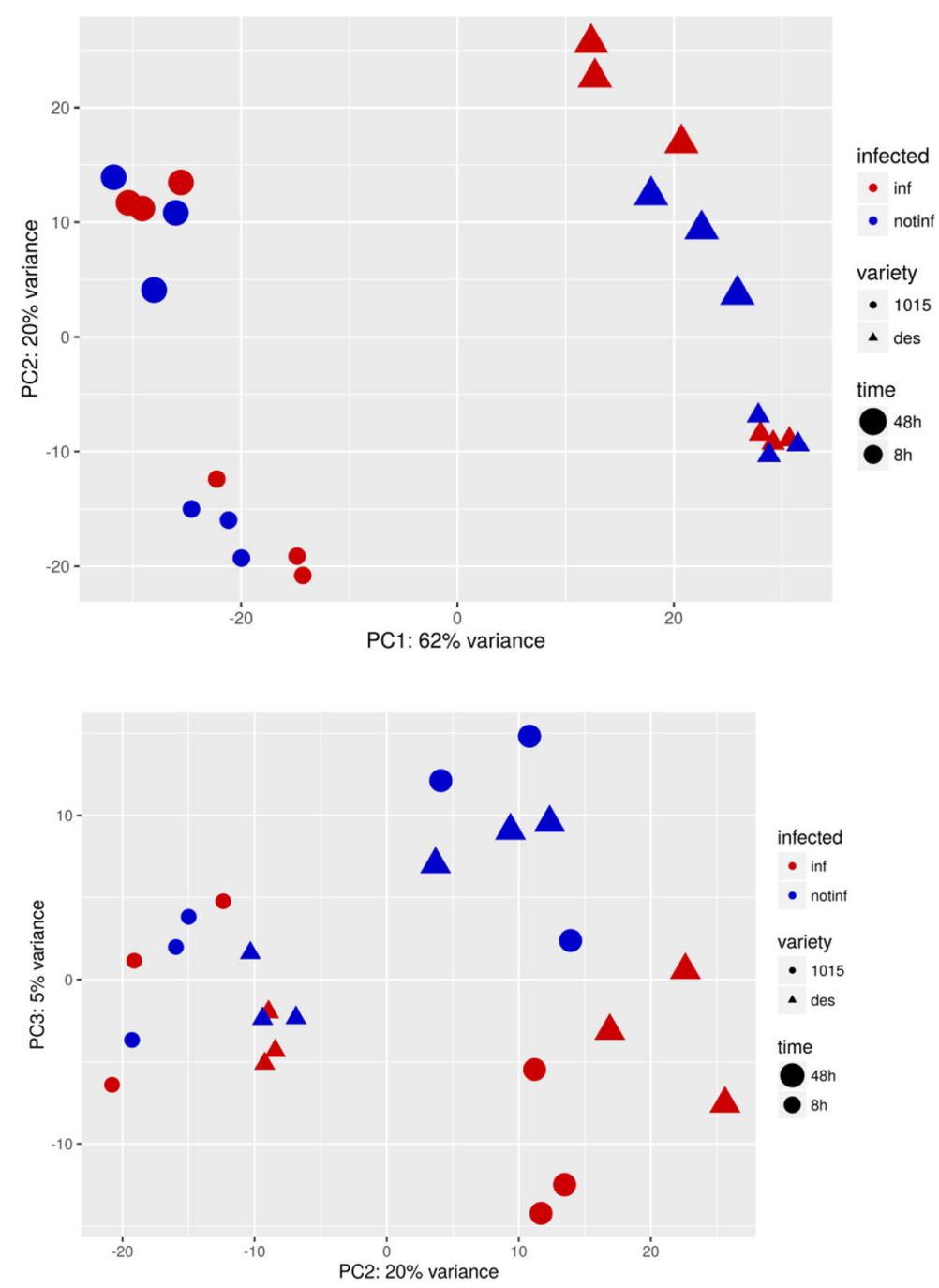

Six potato transcripts were differentially expressed compared to control plants in the resistant interaction $8 \mathrm{~h}$ after inoculation, whereas there were no differences in expression in inoculated and control plants in the susceptible interaction (Table 1). This reflects an earlier recognition of the pest in the resistant combination than in the susceptible interaction and is in line with early signaling down-stream resistance-gene encoded receptors. The most up-regulated gene was a gene annotated as TSRF1 (PGSC0003DMG400017231), coding for an ERF type of transcription factor. TSRF1 binds to the GCC box sequence, which is present in the promotor region of many PR genes (Zhang et al. 2004). The other up-regulated genes were annotated as a Nodulation signaling pathway 2 protein (PGSC0003DMG400012071), a gene with similarity to GRAS transcription factors.
These findings are in line with fast transcriptional reprogramming similar to pathogen defense, possibly due to the presence of the $H I$ gene in the resistant clone. Among the down-regulated genes were one with Myb R2R3 homology (PGSC0003DMG400003202) and a plant defensin family-member (PGSC0003D

Table 1 Number of differentially expressed genes for contrasts between inoculated and non-inoculated controls at $8 \mathrm{~h}$ and $48 \mathrm{~h}$ for Désirée and SW93-1015

\begin{tabular}{lllll}
\hline Conditions & $\begin{array}{l}\text { Désirée } \\
(8 \mathrm{~h})\end{array}$ & $\begin{array}{l}\text { Désirée } \\
(48 \mathrm{~h})\end{array}$ & $\begin{array}{l}\text { SW93- } \\
1015(8 \mathrm{~h})\end{array}$ & $\begin{array}{l}\text { SW93-1015 } \\
(48 \mathrm{~h})\end{array}$ \\
\hline Up-regulated & 0 & 1392 & 2 & 771 \\
Down-regulated & 0 & 526 & 4 & 247 \\
Total & 0 & 1918 & 6 & 1018 \\
\hline
\end{tabular}




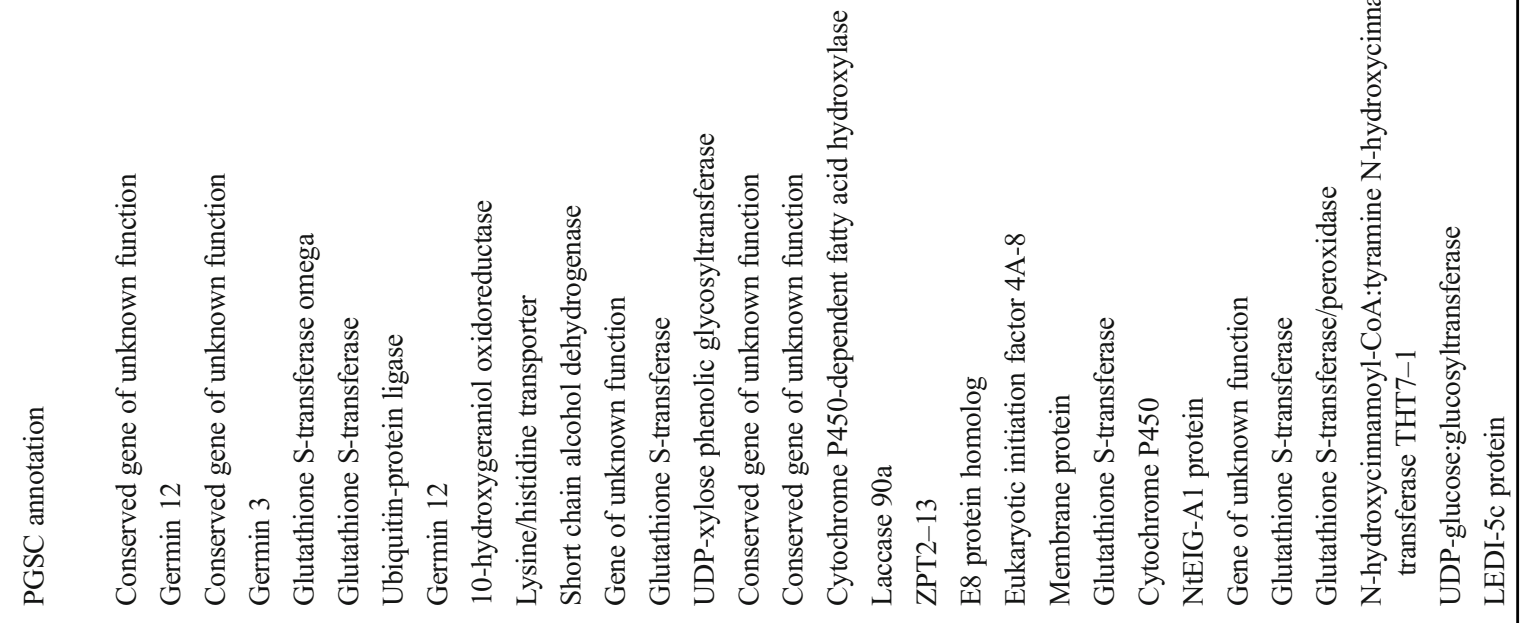

焉 $\quad$ o

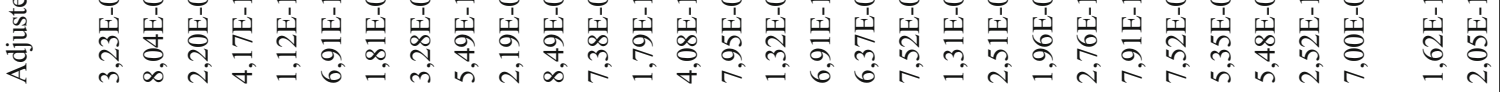

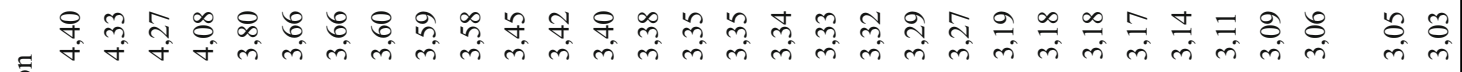
. 올 ปี

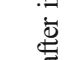

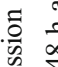

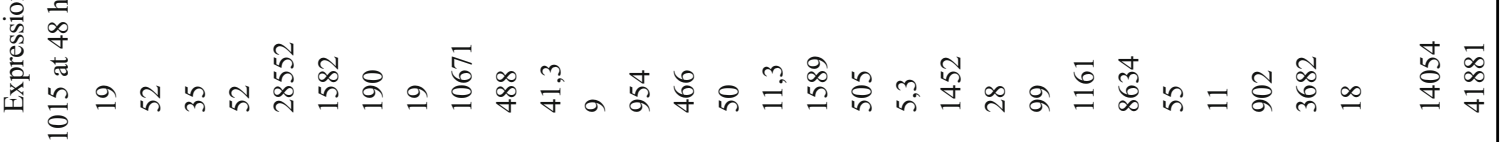
ติ $\sum_{0}^{n}$

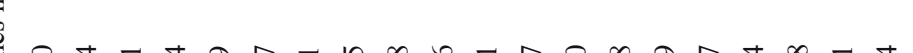

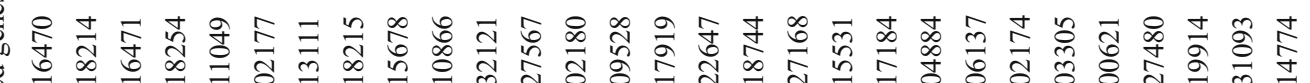

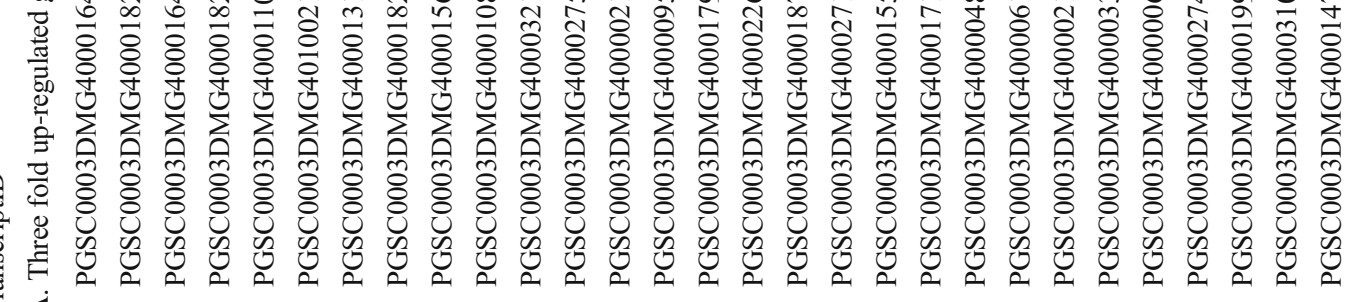

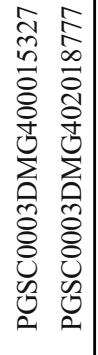




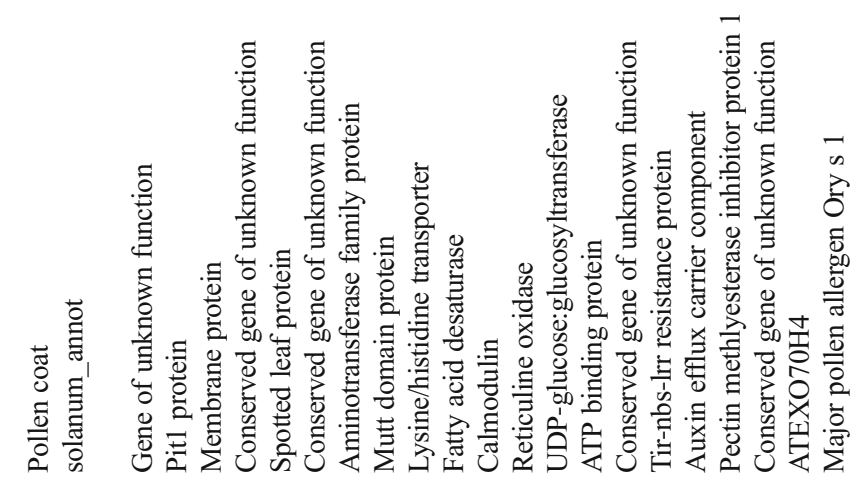

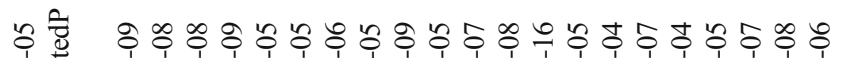

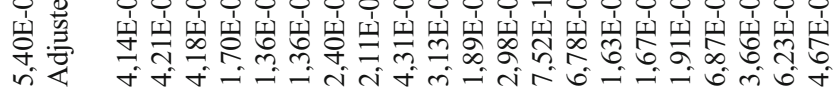

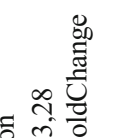

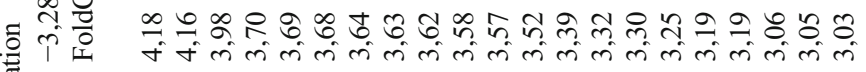

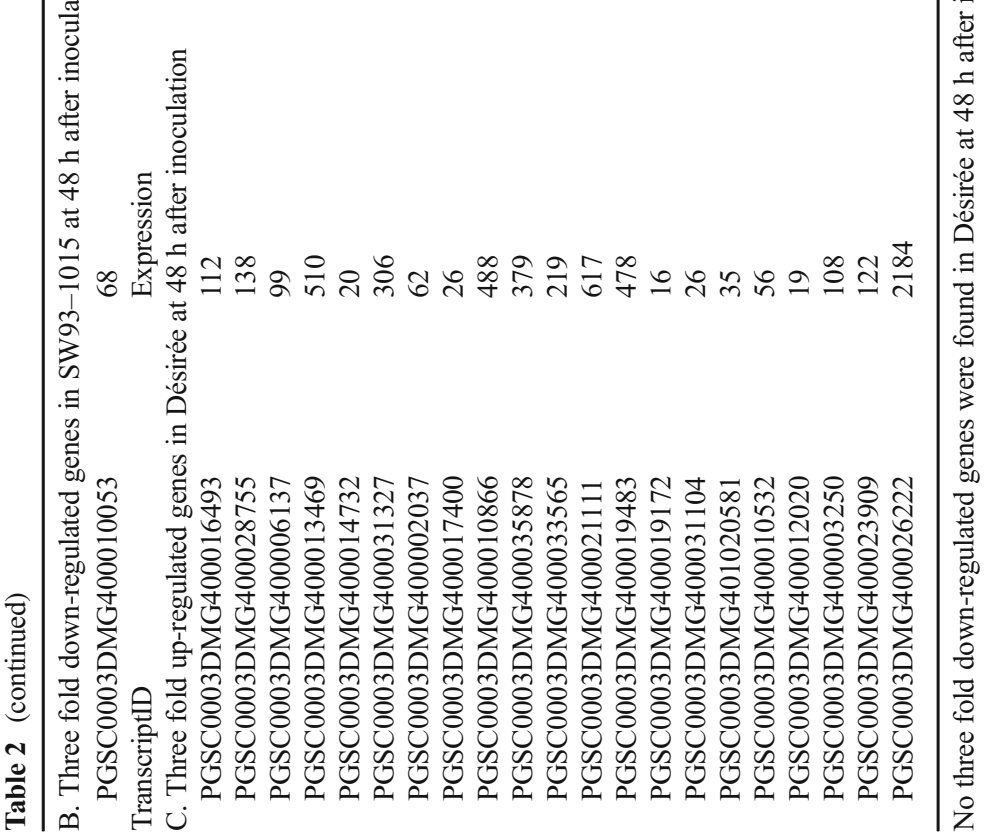


MG400024205). This might reflect a fast repression of pathways related to jasmonic acid/ethylene in the resistant response to nematodes, which is similar to biotic pathogens and different from necrotrophic pathogens (e.g. Moffat et al. 2012). The other two down-regulated genes were PGSC0003DMG400003202 (gene of unknown function) and PGSC0003DMG400024419 (Cembratrienol synthase 2a).

In contrast to the small differences after $8 \mathrm{~h}$, a large transitional reprogramming took place $48 \mathrm{~h}$ post inoculation (Tables 1 and 2, Fig. 3). Almost twice as many transcripts were differentially expressed in the susceptible interaction than in the resistant interaction. Out of these, $72 \%$ were up-regulated in the resistant interaction while $76 \%$ were up-regulated in the susceptible interaction (Table 1). This is a higher proportion of up-regulation than has been observed in, for example, Phytophthora infestans-potato interactions (Ali et al. 2014) and treatments with plant resistance inducers in potato (Bengtsson et al. 2014). The overlap between the differentially expressed genes in the two combinations was 439 out of 1018 for SW93-1015, and 1918 for Désirée. Enriched
GO terms in both combinations include glucosyl- and glutathione transferase activity (Fig. 3).

With a more than threefold increase, several glutathione-S transferases (GSTs) were the most upregulated genes in the resistant combination (Table 2). Three manganese binding proteins germins were also highly up-regulated (Table 2). Overexpressing of germins can induce PR-1 to PR-4 and PDF1-2, and sugarbeet germins have been suggested to be part of an ETI response to nematodes (Knecht et al. 2010). Germins has also been implicated in several other defense reactions (Breen and Bellgard 2010). The significant GO term manganese binding (Fig. 3), which was present only in the resistant combination, reflects the many germins that were identified in the top list of individual transcripts.

A cysteine protease was also heavily induced in the resistant combination (Table $2 \mathrm{a}$ ), and cysteine proteases have been shown to be involved in resistance to cyst nematodes when an effector protein (Gr-VAP1) of G. rostochiensis were recognized by $\mathrm{Rcr} 3^{\mathrm{pim}}$ and CF-2 extracellular receptors in tomato (Lozano-Torres et al. 2012). One ubiquitin ligase with potential function in

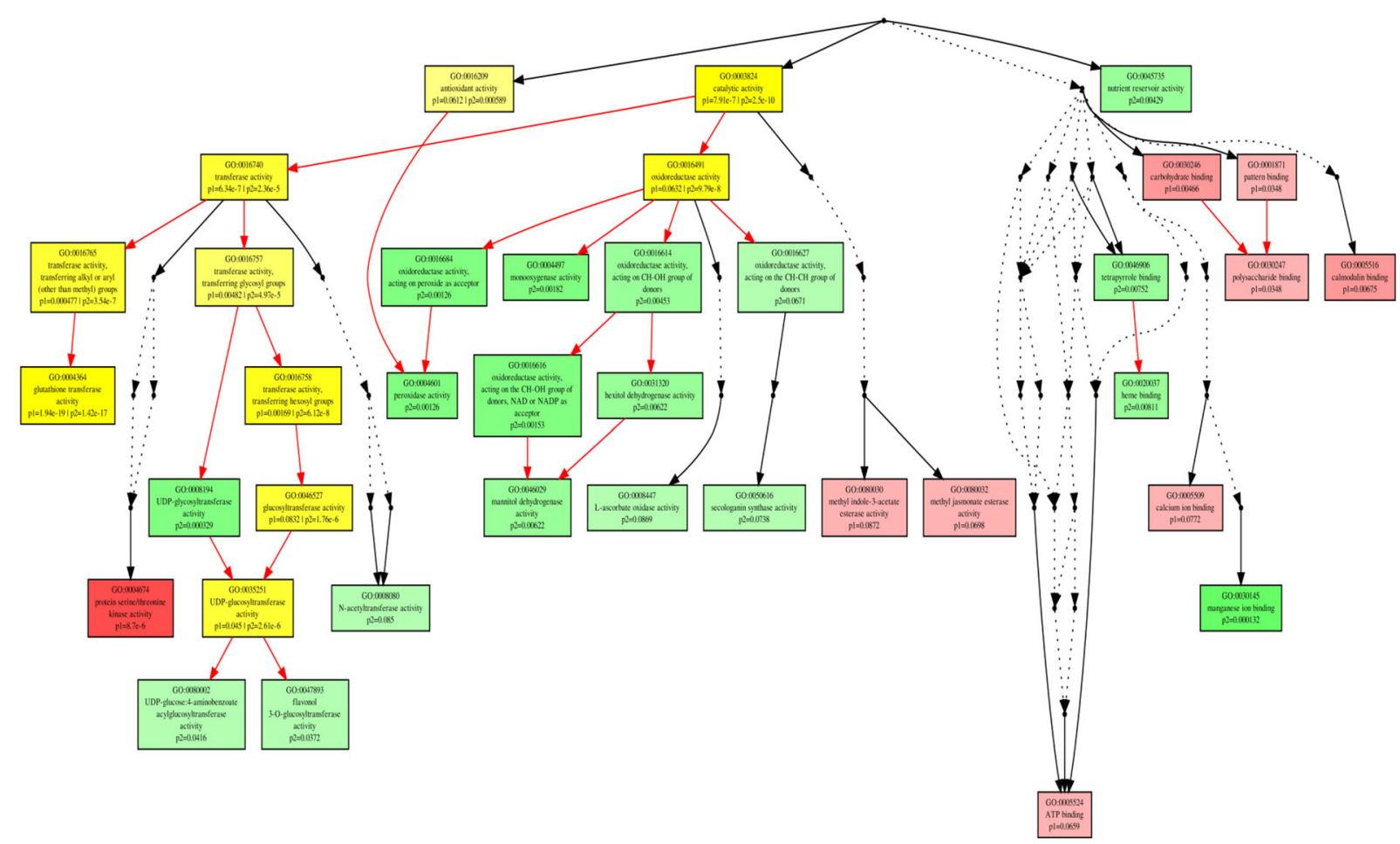

Fig. 3 Significantly enriched Molecular function GO terms at $48 \mathrm{~h}$ post inoculation of Solanum tuberosum roots of Désirée (susceptible) and S. tuberosum SW93-1015 (resistant) with inoculation with Globodera rostochiensis Ro1/4. Green equals GO terms only found in SW93-1015, red equals GO terms enriched only in Désirée and yellow boxes equals GO terms enriched in both genotypes compared to untreated control. Stronger color indicates lower $P$ value 
plant hormonal control was also among the up-regulated genes only present in resistant combination (Table 2). An E3 ubiquitin ligase is repressed in Arabidopsis leading to suppression of basal defense during susceptible interactions with Heterodera schachtii (Hewezi et al. 2016). A gene annotated as a Laccase was also upregulated, and those type of genes has been suggested to strengthen the cell wall through lignification which would make it harder for cyst nematodes to cross the cell wall barrier (Mayer and Staples 2002). Another gene annotated as a pollen coat gene, was heavily downregulated in the resistant combination (Table $2 b$ ).

Our data suggest complex processes take place in the susceptible interaction at $48 \mathrm{~h}$ (Table 1, Table 2, and Fig. 3). A Pit1 homologue (homebox protein) was the second most up-regulated protein in the susceptible potato (Table 2c). A TIR-NBS-LRR protein was also up-regulated only in the susceptible interaction. This protein is probably a receptor and has a similar structure to resistance genes, but with the regulation in this case it is tempting to speculate that it might function as a susceptibility factor. Similarly, an auxin efflux carrier important for cell differentiation and enlargement might function as susceptibility factor as auxin efflux carriers might facilitate formation of feeding structures. Fewer cyst nematodes were produced in Arabidopsis roots if the polar auxin transport system was mutated (Goverse et al. 2000). Another up-regulated gene was annotated as a pectin methylesterase inhibitor protein (Table 2), potentially indicating a role for pectin in re-modelling of the cell wall, again for facilitate the build-up of feeding structures. Enriched GO terms only in the susceptible interaction include protein serine/kinase activity, calcium and calmodulin binding (Fig. 3).

\section{Conclusion}

We showed that a potato breeding clone is resistant to Globodera rostochiensis pathotype Rol/4 and contains the $H 1$ gene. We also present a number of transcripts and processes that were changed in the hours and days after PCN infection during susceptible and resistant potato interactions. Future work will include functional validation of these candidates.

Acknowledgements We thank the Swedish research council Formas, the Swedish foundation for environmental Strategic research (Mistra), Carl Tryggers Foundation and the Crafoord foundation for financial support.

\section{Compliance with ethical standards}

Conflict of interest The authors declare that they have no conflict of interest.

Open Access This article is distributed under the terms of the Creative Commons Attribution 4.0 International License (http:// creativecommons.org/licenses/by/4.0/), which permits unrestricted use, distribution, and reproduction in any medium, provided you give appropriate credit to the original author(s) and the source, provide a link to the Creative Commons license, and indicate if changes were made.

\section{References}

Abreha, K. B., Alexandersson, E., Vossen, J. H., Anderson, P., \& Andreasson, E. (2015). Inoculation of transgenic resistant potato by Phytophthora infestans affects host plant choice of a generalist moth. PLoS One, 10(5), e0129815. https://doi. org/10.1371/journal.pone.0129815.

Ali, A., Moushib, L. I., Lenman, M., Levander, F., Olsson, K., Carlson-Nilson, U., Zoteyeva, N., Liljeroth, E., \& Andreasson, E. (2012). Paranoid potato: Phytophthoraresistant genotype shows constitutively activated defense. Plant Signaling and Behavior, 7(3), 400-408.

Ali, A., Alexandersson, E., Sandin, M., Resjö, S., Lenman, M., Hedley, P., Levander, F., \& Andreasson, E. (2014). Quantitative proteomics and transcriptomics of compatible and incompatible interactions between potato and Phytophthora infestans. BMC Genomics, 15(1), 497.

Amar, D., Frades, I., Danek, A., Goldberg, T., Sharma, S. K., Hedley, P. E., Proux-Wera, E., Andreasson, E., Shamir, R., Tzfadia, O., \& Alexandersson, E. (2014). Evaluation and integration of functional annotation pipelines for newly sequenced organisms: The potato genome as a test case. $B M C$ Plant Biology, 14(1), 329.

Anders, S., Pyl, P. T., \& Huber, W. (2015). HTSeq-A Python framework to work with high-throughput sequencing data. Bioinformatics, 31(2), 166-169.

Bengtsson, T., Weighill, D., Proux-Wéra, E., Levander, F., Resjö, S., Burra, D. D., et al. (2014). Proteomics and Transcriptomics of the BABA-induced resistance response in potato using a novel functional annotation approach. $B M C$ Genomics, 15, 315.

Bolger, A. M., Lohse, M., \& Usadel, B. (2014). Trimmomatic: A flexible trimmer for Illumina sequence data. Bioinformatics, 30(15), 2114-2120.

Breen, J., \& Bellgard, M. (2010). Germin-like proteins (GLPs) in cereal genomes: Gene clustering and dynamic roles in plant defence. Funct Integra Genomics, 10, 463-476.

Eriksson, D., Carlson-Nilsson, U., Ortíz, R., \& Andreasson, E. (2016). Overview and breeding strategies of table potato production in Sweden and the Fennoscandian region. Potato Research, 59(3), 279-294.

Goverse, A., Overmars, H., Engelbertink, J., Schots, A., Bakker, J., \& Helder, J. (2000). Both induction and morphogenesis of 
cyst nematode feeding cells are mediated by auxin. Molecular Plant-Microbe Interactions, 13, 1121-1129.

Heungens, K., Mugniéry, D., Van Montagu, M., Gheysen, G., \& Niebel, A. (1996). A method to obtain disinfected Globodera infective juveniles directly from cysts. Fundamental and Applied Nematology, 19, 91-93.

Hewezi, T. (2015). Cellular signaling pathways and posttranslational modifications mediated by nematode effector proteins. Plant Physiology, 169, 1018-1026.

Hewezi, T., Piya, S., Qi, M., Balasubramaniam, M., Rice, J. H., \& Baum, T. J. (2016). Arabidopsis miR827 mediates posttranscriptional gene silencing of its ubiquitin E3 ligase target gene in the syncytium of the cyst nematode Heterodera schachtii to enhance susceptibility. The Plant Journal, 88, 179-192.

Jones, J. T., Haegeman, A., Danchin, E. G., et al. (2013). Top 10 plant-parasitic nematodes in molecular plant pathology. Molecular Plant Pathology, 14, 946-961.

Knecht, K., Seyffarth, M., Desel, C., Thurau, T., Sherameti, I., Lou, B., Oelmüller, R., \& Cai, D. (2010). Expression of BvGLP-1 encoding a germin-like protein from sugar beet in Arabidopsis thaliana leads to resistance against phytopathogenic fungi. Molecular plant- microbe interactions, 23, 446457.

Love, M. I., Huber, W., \& Anders, S. (2014). Moderated estimation of fold change and dispersion for RNA-seq data with DESeq2. Genome Biology, 15, 550. https://doi.org/10.1186 /s13059-014-0550-8.

Lozano-Torres, J. L., Wilbers, R. H., Gawronski, P., et al. (2012). Dual disease resistance mediated by the immune receptor Cf2 in tomato requires a common virulence target of a fungus and a nematode. Proceedings of the National Academy of Sciences, 109, 10119-10124.

Manduric, S. (2004). Some potato cyst nematode, Globodera rostochiensis and G. pallida, issues related to Swedish potato production. $\mathrm{PhD}$ thesis. In Swedish University of Agricultural Sciences ISBN 91-576-6479.

Mayer, A. M., \& Staples, R. C. (2002). Laccase: New functions for an old enzyme. Phytochemistry, 60, 551-565.

Mitchum, M. G., Wang, X., Wang, J., \& Davis, E. L. (2012). Role of nematode peptides and other small molecules in plant parasitism. Annual Review of Phytopathology, 50, 175-195.

Mitchum, M. G., Hussey, R. S., Baum, T. J., Wang, X., Elling, A. A., Wubben, M., \& Davis, E. L. (2013). Nematode effector proteins: An emerging paradigm of parasitism. New Phytologist, 199, 879-894.

Moffat, C. S., Ingle, R. A., Wathugala, D. L., Saunders, N. J., Knight, H., \& Knight, M. R. (2012). ERF5 and ERF6 play redundant roles as positive regulators of JA/et-mediated defense against Botrytis cinerea in Arabidopsis. PLoS One, 7, e35995.
Portillo, M., Cabrera, J., Lindsey, K., Topping, J., Andrés, M. F., Emiliozzi, M., Oliveros, J. C., García-Casado, G., Solano, R., Koltai, H., Resnick, N., Fenoll, C., \& Escobar, C. (2013). Distinct and conserved transcriptomic changes during nematode-induced giant cell development in tomato compared with Arabidopsis: A functional role for gene repression. New Phytologist, 197, 1276-1290.

Rodríguez-López, M., Baroja-Fernández, E., Zandueta-Criado, A., Moreno-Bruna, B., Zheng, Q., \& Wang, X. J. (2008). GOEAST: a web-based software toolkit for Gene Ontology enrichment analysis. Nucleic acids research, 36(suppl 2), W358-W363.

Sharma, S. K., Bolser, D., de Boer, J., Sønderkær, M., Amoros, W., Carboni, M. F., D’Ambrosio, J. M., de la Cruz, G., di Genova, A., Douches, D. S., Eguiluz, M., Guo, X., Guzman, F., Hackett, C. A., Hamilton, J. P., Li, G., Li, Y., Lozano, R., Maass, A., Marshall, D., Martinez, D., McLean, K., Mejía, N., Milne, L., Munive, S., Nagy, I., Ponce, O., Ramirez, M., Simon, R., Thomson, S. J., Torres, Y., Waugh, R., Zhang, Z., Huang, S., Visser, R. G. F., Bachem, C. W. B., Sagredo, B., Feingold, S. E., Orjeda, G., Veilleux, R. E., Bonierbale, M., Jacobs, J. M. E., Milbourne, D., Martin, D. M. A., \& Bryan, G. J. (2013). Construction of reference chromosome-scale pseudomolecules for potato: Integrating the potato genome with genetic and physical maps. G3 (Bethesda, Md.), 3(11), 2031-2047.

Swiecicka, M., Filipecki, M., Lont, D., Van Vliet, J., Qin, L., Goverse, A., et al. (2009). Dynamics in the tomato root transcriptome on infection with the potato cyst nematode Globodera rostochiensis. Molecular Plant Pathology, 10(4), 487-500.

Thaler, J. S., Humphrey, P. T., \& Whiteman, N. K. (2012). Evolution of jasmonate and salicylate signal crosstalk. Trends in Plant Science, 17, 260-270.

Thimm, O., Bläsing, O., Gibon, Y., Nagel, A., Meyer, S., Krüger, P., Selbig, J., Müller, L. A., Rhee, S. Y., \& Stitt, M. (2004). Mapman: A user-driven tool to display genomics data sets onto diagrams of metabolic pathways and other biological processes. The Plant Journal, 37(6), 914-939.

Walters, D. (2010). Plant Defense. Hoboken, GB. WileyBlackwell.

Xu, X., Pan, S., Cheng, S., Zhang, B., Mu, D., Ni, P., et al. (2011). Genome sequence and analysis of the tuber crop potato. Nature, 475, 189-195.

Zhang, H., Zhang, D., Chen, J., Yang, Y., Huang, Z., Huang, D., Wang, X. C., \& Huang, R. (2004). Tomato stress-responsive factor TSRF1 interacts with ethylene responsive element GCC box and regulates pathogen resistance to Ralstonia solanacearum. Plant Molecular Biology, 55(6), 825-834. 